\title{
Lump System Analysis Modelling for Enhanced Ballistic Performance of Clay Box Doped with Different Types of Additives
}

\author{
Popoola Abduljelili ${ }^{1,2}$, Olatona Gbadebo I. ${ }^{1}, \&$ Muhammed T. Abdullahi ${ }^{2}$ \\ ${ }^{1}$ Osun State University, Osogbo, Nigeria \\ ${ }^{2}$ King Fahd University of Petroleum and Minerals, Dhahran, Kingdom of Saudi Arabia \\ Correspondence: Popoola Abduljelili, Osun State University, Osogbo, Nigeria. E-mail: \\ popoolaabduljeleel2000@gmail.com
}

Received: May 28, 2019

Accepted: July 2, 2019

Online Published: July 31, 2019

doi:10.5539/jmsr.v8n3p23

URL: https://doi.org/10.5539/jmsr.v8n3p23

\begin{abstract}
The temperature of clay box used in the ballistic testing of body amour drops sharply upon removal from the oven. This implies that the clay has to be reinserted into the oven for another heating, which slows down the ballistic testing procedure. This paper attempts to solve the problem by studying the effect of addition of different percentages of rubber cuttings, saw dust and berley reeds additives on the cooling rate of clay used in clay box construction. The cooling rate is a measure of the ballistic performance of the clay box. The properties of the clay box such as the density, thermal conductivity and specific heat capacity are factored into the lump system analysis model. Minimum cooling rate of about $2.04 \times 10^{-03}$ and $1.89 \times 10^{-030} \mathrm{C} / \mathrm{s}$ were obtained when $0 \%$ and $10 \%$ rubber cuttings were used as dopands respectively. Rubber cuttings also proved to be the best additives that can be used to enhance the ballistic performance of clay box used in the ballistic testing of body armour.
\end{abstract}

Keywords: Ballistic Testing, Body Armor, Additives, Lump System Analysis, Cooling Rate

\section{Introduction}

The evaluation of the performance of hard and soft body armor is done by placing clay at the back of the armor and firing the clay used with bullets or any other ballistic material. The depth to which the bullets penetrates the clay is chosen as scale of performance of the body armour. Therefore, to evaluate the performances of body armours, the first step is to place a clay box behind a material to be tested (Dale et al., 2011). Canonically, the clay box is molded into a block shape by a Roma Plastilina or modelling clay with $610 \mathrm{~mm}$ by $610 \mathrm{~mm}$ by $140 \mathrm{~mm}$ dimension and has a $19 \mathrm{~mm}$ thick backing made of either aluminium or steel frame. It also has $3.175 \mathrm{~mm}$ thick U-channel according to the Law Enforcement Standards Office (LESO) at the National Institute of Standards and Technology (NIST) (Dale et al., 2011; NIJ Standard-0101.06., 2008; Garcia-avila, Portanova, \& Rabiei, 2014).

Though clay has many favourable thermal and mechanical properties as demonstrated in reports (Silva \& Perera, 2018; Rahman, 2014) where clay pots were confirmed to have a good heat retention ability. However, the incessant changing properties of the plastilina (modeling clay) makes it vulnerable to frequent pre-conditioning to a temperature of about $40^{\circ} \mathrm{C}$ in order to perform a ballistic test. Consequently, the performance of the clay box has to be validated by a series of calibration drop test upon removal from the oven after which the clay box will only be used for the actual ballistics test if it passed the calibration drop test i.e. if the identations produced are within the acceptable limits. Despite all these, the National Institute of Justice (NIJ), still demands the calibration drop tests be repeated after every ballistic test according to its 0101.06 standard (Dale et al., 2011; Garcia-avila, Portanova, \& Rabiei, 2014; Mukasey, Sedgwick, \& Hagy, n. d.). However, this is not the case for other testing protocols. Hence, the integrity of the ballistic test result is at bleak courtesy of the unavoidable cooling the clay box usually encounters immediately upon removal from the oven. The unavoidable cooling of the thus actually affects the ballistic performance. The main material used in the construction of the clay box is the clay and the main properties that determine the rate of cooling of the clay are the thermal conductivity, the heat capacity and the density of the clay.

Clay is a type of soil that is commonly most finely grained. It has a unique property of being malleable when it is wet and becomes very hard when it is dry and at high temperature. Its formation is usually through natural process involving weathering, deposition and sedimentation of rocks over some geological period of time. The major 
composition of clay are oxides of iron, alumina $\left(\mathrm{Al}_{2} \mathrm{O}_{3}\right)$, silica $\left(\mathrm{SiO}_{2}\right)$, oxides of alkali and alkaline earth metals and water $\left(\mathrm{H}_{2} \mathrm{O}\right)$. Minerals such as mica, feldspar, quartz are also available in the clay (Aramide, 2012; Johari, Said, Hisham, Bakar, \& Ahmad, 2010).

Many research works have been conducted on the effect additives on clay properties such as thermal conductivity, density, porosity, thermal diffusivity, dry shrinkage and heat capacity of the clay by addition of various types of additives such as ashes, saw dust, rice husks, berley reed, rubber cuttings etc. to make the clay better refractory or for other suitable applications (Silva \& Perera, 2018; Rahman, 2014; Aramide, 2012; Folaranmi, 2009; Qatta, 2012; Ahmad, Iqbal, \& Muhammad, 2017; Silva \& Mallwattha, 2018; Velasco, Ortíz, Giró, \& Velasco, 2014; Journal \& Scientific, 2011). Meanwhile, to the best of our notice, no research work has investigated the effect of additives on the cooling rate of clay in an attempt to improve the ballistic performance of the clay box. The coupling of thermal conductivity, heat capacity and density all combine to affect the cooling rate of a body. These quantities however vary with the types and the quantity of additives on the clay (Silva \& Mallwattha, 2018; Velasco, Ortíz, Giró, \& Velasco, 2014; Oskouei, Afzali, \& Madadipour, 2017; Kazmi, Abbas, Saleem, Munir, \& Khitab, 2016; Toure, Sambou, Faye, \& Thiam, 2017). In fact, literature showed that the thermal conductivity of the clay decreases as the percentage by mass of the additives increases. If the thermal conductivity of clay can be affected by the addition of additives, then, there should be an effect of adding these additives on the ballistic performance of the clay used in clay box construction since the rate of cooling of the plastilina is affected by the thermal conductivity of the clay used in the modeling. Also, literatures (Silva \& Perera, 2018; Rahman, 2014; Aramide, 2012; Johari, Said, Hisham, Bakar, \& Ahmad, 2010; Folaranmi, 2009; Qatta, 2012; Ahmad, Iqbal, \& Muhammad, 2017; Velasco, Ortíz, Giró, \& Velasco, 2014; Oskouei, Afzali, \& Madadipour, 2017; Chen \& Ahmad, 2017; Olgun, 2013) have proved that other thermo-physical properties of clay such as density and heat capacity are affected by the percentage by mass of additives in the clay.

This paper is therefore aimed at investigating the effects of additives on the ballistic performance of the clay box when various proportions of berley reeds, saw dust and rubber cuttings additives are used dopants in clay. The intrinsic properties of clay such as: density, thermal conductivity and thermal conductivity are integrated into the lump system analysis model. The Lump system analysis was then used to compute the cooling rate of clay with various percentages of additives using a code written $\mathrm{c}++$ and compiled with devcpp 4.9.9.2. This computational modelling was based on the results of experimental measurements of density, heat capacity and thermal conductivity of clay as reported by (Silva \& Perera, 2018; Rahman, 2014; Folaranmi, 2009; Ahmad, Iqbal, \& Muhammad, 2017; Journal \& Scientific, 2011).

\section{Methodology}

To apply the lump system analysis model, one needs to obtain the value the biot number. The biot number gives a measure but in form of ratio of heat resistance inside of a body to the heat resistance at the surface of the body. It can be used to check the applicability of the lump system analysis since it determine whether temperature will vary much in space (i.e it checks the extent to which the temperature remains a function of position) when heat is applied. Generally, to apply the lump system analysis model, the evaluated biot number must be greater or equal to 1. While biot number of 0.001 indicates the exactness of lump system applicability, the model only gives an approximate result for biot number above 0.001 . If accuracy is not of major concern, then the model may even be applied for biot number greater than one. In this case, investigating the effect of dopands on the cooling rate of clay does not call for stringent accuracy. Hence, the lump system modelling can be applied (Subramanian, n. d.; Rickards, 2013).

\subsection{The Calculation of Biot Number}

The dimension of the clay box conventionally is given by $610 \mathrm{~mm}$ by $610 \mathrm{~mm}$ by $140 \mathrm{~mm}$ (Dale et al., 2011). The coefficient of heat transfer, $\mathrm{h}$ is given by

$$
h=1.42\left(\frac{\Delta T}{L}\right)^{\frac{1}{4}}
$$

Where $\Delta \mathrm{T}$ is the change in temperature and $\mathrm{L}$ is the length of the box (Velasco, Ortíz, Giró, \& Velasco, 2014), at a very small change in temperature, say $0.5^{\circ} \mathrm{C}$, between the clay box and its surrounding upon removal from the oven, then the Biot number is given as

$$
B i=\frac{h L_{c}}{K}
$$


Where $h$ is the coefficient of heat transfer, $L_{c}$ is characteristic length, $K$ is thermal conductivity (Ahmad, Iqbal, \& Muhammad, 2017)

Evaluating h from eqn. 1 gives, coefficient of heat transfer, $h=1.95 \mathrm{Wm}^{-2} \mathrm{~K}^{-1}$

The biot number evaluated from Equation 2 is $B i=1.09$ which is approximately equal to 1 . Even though, this result does not look much favorable because the condition is $\boldsymbol{B i} \geq \boldsymbol{0}$ but out of this, $\boldsymbol{B i}>\boldsymbol{0}$ is only an approximate. If $\mathrm{Bi}<0.1$, it implies heat conduction rates in the body is faster than heat convection rates away from the surface of the body. The type of body is said to be "thermally thin" and temperature can be assumed to be uniform through the volume of the body. However, when $\mathrm{Bi}>0$, this assumption made earlier cannot be made. In this case, the application of lump system analysis to the modeling is only a matter of approximation. The approximation is however convenient for us just to demonstrate the effect of additive on the ballistic performance of the clay box (Subramanian, n. d.; Rickards, 2013; Glen, 1971).

There are other approaches to measuring the ballistic performance of the clay box but the lumped system analysis provides the simplest approach for this measurement (Dale et al., 2011; Glen, 1971). The assumptions used by this approach is that the heat transfer to the environment by a body is controlled by the convection heat transfer coefficients and thermal capacities of the material provide these two are high enough (Glen, 1971). This approach however may be too simple to be valid practically but can still be used to demonstrate the effect of additive on the ballistic performance of the clay box. The limitation of this approach is that it assumes temperature is only a function of time and not a function of distance. This assumption is not likely to be achieved since clay itself is not a very good conductor and also the thickness of the clay box is about $140 \mathrm{~mm}$.

\subsection{The Model}

The lump system analysis model is written after a slight modification as;

$$
\frac{\left(T-T_{\infty}\right)}{\left(T_{o}-T_{\infty}\right)}=\exp \left[\frac{-h A \tau}{\rho c V}\right]
$$

Where $T_{\infty}$ is the ambient (environment) temperature, $T_{o}$ is the initial temperature of the clay box, $A$ is the exposed surface area, $\tau$ is the elapsed time, $\rho$ is the density of the clay box, $c$ is the heat capacity of the box and $V$ is the volume (Dale et al., 2011). It is important to note that eqn (3) is a modification of the equation below though applied in a very different perspective, all stem from the same basis (the lump system analysis)

$$
t=\frac{m c_{p}}{h A_{s}} \operatorname{In}\left[\frac{T_{m}-T(t)}{T_{m}-T_{i}}\right]
$$

$\mathrm{m}$ is the mass of the body, $\mathrm{h}$ is the convection heat transfer coefficient, $\mathrm{c}_{\mathrm{p}}$ is the heat capacity, $\mathrm{A}_{\mathrm{s}}$ is the surface area of the body, $T_{m}$ is the temperature of the surrounding medium, $T_{i}$ is the initial temperature of the body and $T(t)$ is the temperature at time, $\mathrm{t}$ (Dale et al., 2011; Subramanian, n. d.; Glen, 1971).

Even though, there are many materials that make up the clay box, but we will be concerned with the clay since it forms the greater percentage of the clay box for the purpose of demonstration. From the above model, the only intrinsic properties of the clay are density, thermal conductivity and heat capacity; all others are extrinsic properties (they can be regarded as constants for the plastilina). In order to include the effect of varying thermal conductivity on the ballistic performance of the clay box, we modify Equation 3 as shown below

$$
B i=\frac{h L_{c}}{K} \cong 1
$$

Factoring Equation 5 into Equation 4:

$$
T=\left(T_{0}-T_{\infty}\right) \exp \left[\frac{-h K \tau}{\rho c L_{c}^{2}}\right]+T_{\infty}
$$

Also, the relation $L_{c}=A / V$ was factored into Equation (3) to obtain the above equation. Where $\mathrm{K}, \mathrm{L}_{\mathrm{c}}, \mathrm{A}$ and $\mathrm{V}$ are thermal conductivity, characteristic length, area and volume respectively (Dale et al., 2011; Mukasey, Sedgwick, $\&$ Hagy, n. d.). We shall now use the above model to evaluate the ballistic performance of the clay box by varying 
the values of $\rho, c$ and $K$ due to different percentages of additives (sawdust, berley reeds and rubber cuttings) on the clay used in the construction of the clay box.

\section{Result and Analysis}

The graphs shown below were obtained from the output of the code written in $\mathrm{c}++$ which has been compiled by devcpp version 4.9.9.2 software. In Figures 1a, 2a and 3a, the cooling curves decreases downward towards the room temperature as time increases. As observed in Figure 1a, after about 1.5 hours, the clay with rubber cutting additives has only cooled to $33.51^{\circ} \mathrm{C}, 30.41^{\circ} \mathrm{C}, 33.70^{\circ} \mathrm{C}, 32.68^{\circ} \mathrm{C}$ and $31.60^{\circ} \mathrm{C}$ for $0 \%, 5 \%, 10 \%, 15 \%$ and $20 \%$ rubber cuttings additives respectively, which indicates different cooling for each of the samples. Thus, heat retention ability of the clay samples is very good. As shown in Figures $1 \mathrm{a}, 1 \mathrm{~b}$ and $1 \mathrm{c}$, temperature of the clay samples decay exponentially with time, which is the characteristic of a typical cooling curve. Also from these Figures, the role additives generally play on the cooling rate of clay is explicit. It is shown that different samples of clay doped with percentages of additives have different cooling curve slopes, which is a direct measure of their cooling rate. It is important to state that the ballistic performance has an inverse relationship with the cooling rate. Thus, for an improved ballistic performance, lower cooling rate is essential. As the percentage by mass of additives increases from 10\% upwards, the rate of cooling also increases as shown in Figures 1d, 1e, 1f and 3. This may seem counter intuitive since thermal conductivity decreases as the percentage by mass of additives increases (Silva \& Perera, 2018; Folaranmi, 2009; Ahmad, Iqbal, \& Muhammad, 2017; Journal \& Scientific, 2011) and thermal conductivity has a direct relationship with cooling rate as shown in Fourier's law. One might therefore expect that as the percentage by mass of the additives increases, the cooling rate should reduce since thermal conductivity reduces. However, this cannot always be true since thermal conductivity alone does determine the cooling rate. The cooling rate also depend on density and heat capacity of the clay. For example, heat capacity and density have inverse and direct proportionality with cooling rate respectively. Thus, the higher heat capacity and lower density are essential for lower cooling rate. We can then infer that different properties dominates the cooling rate at different percentage by mass of additives. Cooling rate increases between 0 and $5 \%$, decreases from $5 \%$ till $10 \%$ where it is minimum, then increases afterward. This behavior of cooling rate in response to varying percentage by mass of additives is still not fully understood. Therefore, open to further investigation.

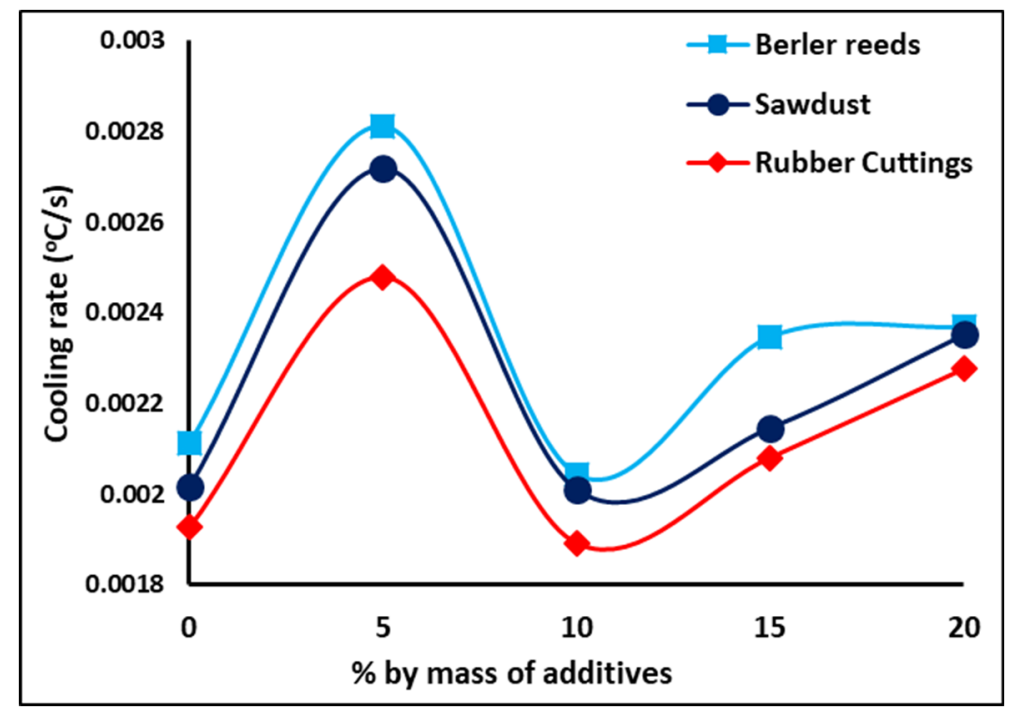

Figure 1 . The graph of cooling rate versus $\%$ by mass of saw dust, berley reeds and rubber cuttings additives

The highest cooling rate was obtained for clay doped with $5 \%$ additives, which implies a bad ballistic performance at that level of dopands. From Figure 1 also, it is depicted that the rate of cooling of clay with $10 \%$ additives is comparable with that with $0 \%$ doping, though the minimum cooling rate is obtained at $10 \%$ doping. This observed two minimal levels of cooling rate is unique and evident for all the additive types as shown in Figures 1, 2d, 2e and $2 \mathrm{f}$. This uniqueness instigates experimentalists to choose between perfect purity and an exact doping with $10 \%$ additives. However, clay is an earth element and therefore expected to have inherent impurity apart from its normal composition. While one is free to choose between $0 \%$ and $10 \%$ for ballistic testing, using clay box doped with $10 \%$ additives seem more practical since achieving a perfectly pure state for clay is definitely more tasking. 


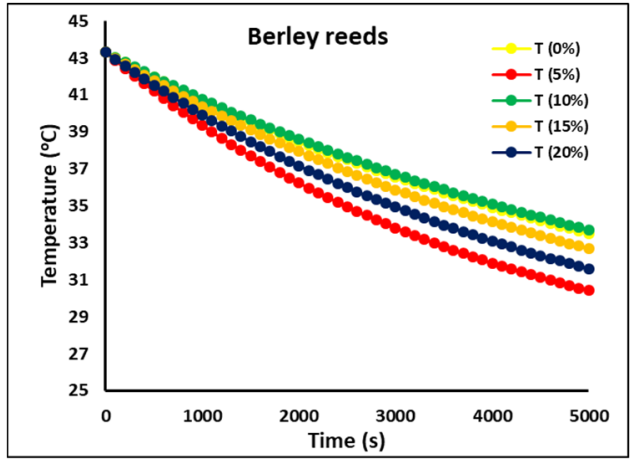

a

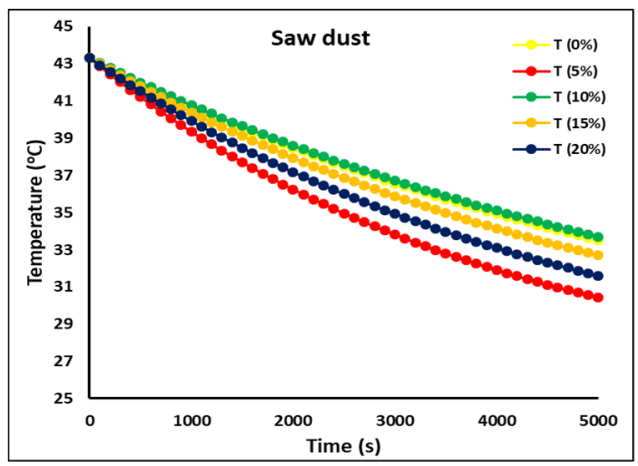

b

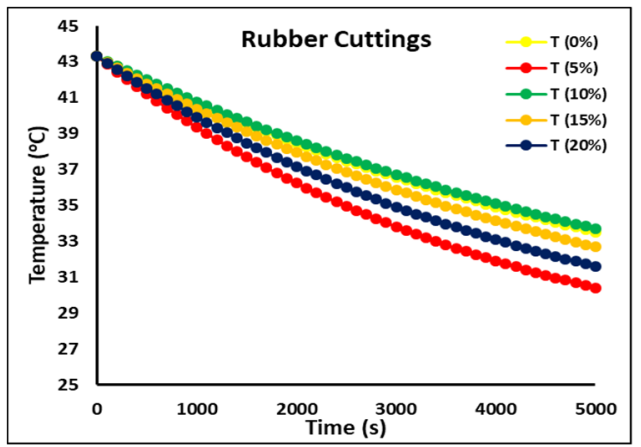

$\mathrm{c}$

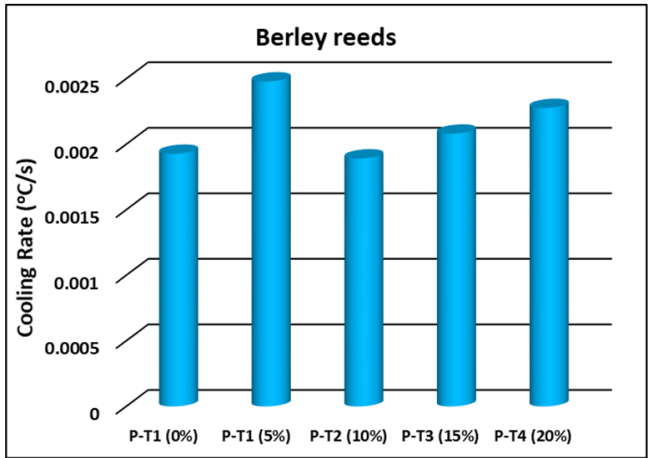

$\mathrm{c}$

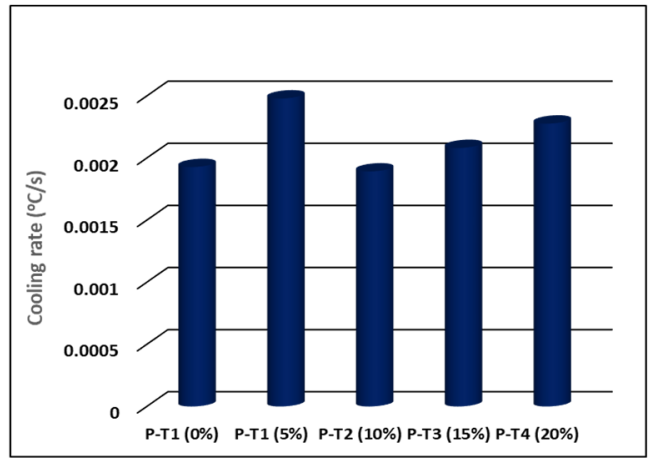

d

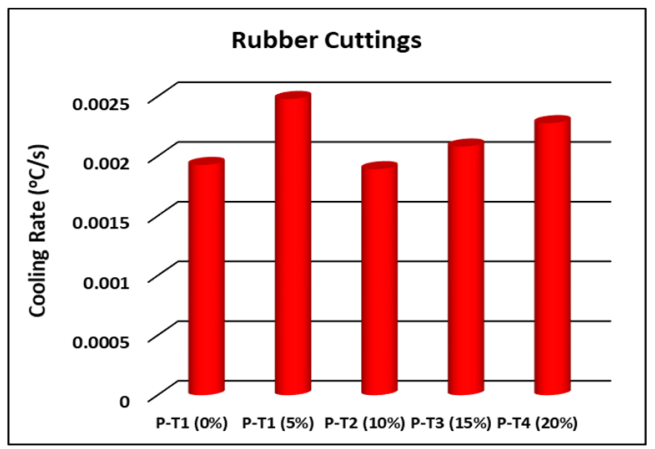

e

Figure 2. (a-c) The graph of cooling rate versus time (d-e) Bar chart representation for different percentages of saw dust, berley reeds and rubber cuttings additives, including bar chat representation

The effect of different additives (saw dust, berley reeds and rubber cuttings) on the ballistic performance of clay are shown in Figure 3. It is evident that the best additives to use as dopands for clay box construction is rubber cuttings, displaying the smallest minimum cooling rate of $1.89 \times 10^{-030} \mathrm{C} / \mathrm{s}$. The same behavior is repeated at different percentages of additives. This demonstrates further that at any percentages of additives, rubber cuttings will always have the lowest cooling rate. Therefore, rubber cuttings is the best additive out of all these three that can be used in the construction of clay box used in ballistic testing of body armour. 

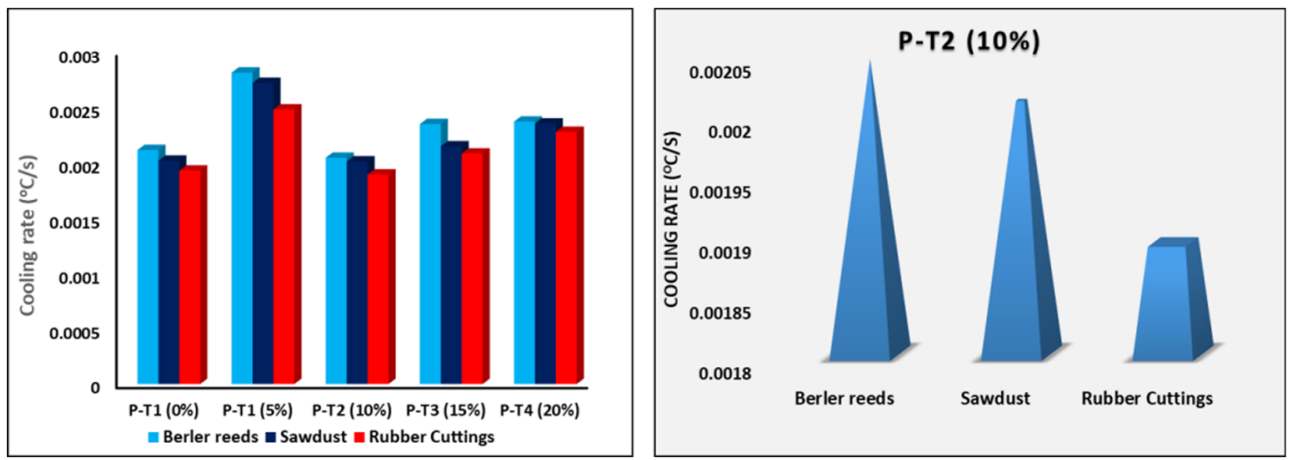

Figure 3. The graph of cooling rate versus time for different percentages of saw dust, berley reeds and rubber cuttings additives, including bar chat representation

\section{Conclusion}

In this work, the effect of different percentage by mass of saw dust, rubber cuttings and berley reeds additives on the cooling rate of clay were investigated using the lump system analysis modelling. The cooling rate serves as the performance metrics for ballistic performance of clay used in the construction of clay box. The smallest minimum cooling rate $\left(1.89 \times 10^{-030} \mathrm{C} / \mathrm{s}\right)$ obtained in this work are from clay doped with $10 \%$ by mass of rubber cuttings, making clay doped with $10 \%$ rubber cuttings the best additive for enhancing the ballistic $\mathrm{p}$ of clay used in clay box construction. Generally, while $10 \%$ by mass of additives always give the smallest values of cooling rate, pure clay also give comparatively low values of cooling rate $\left(2.04 \times 10^{-030} \mathrm{C} / \mathrm{s}\right)$. This enables the ballistic testing experimentalist to choose between a pure clay or $10 \%$ rubber cuttings doped clay in constructing the clay box used for the ballistic testing of body armour.

\section{The Program}

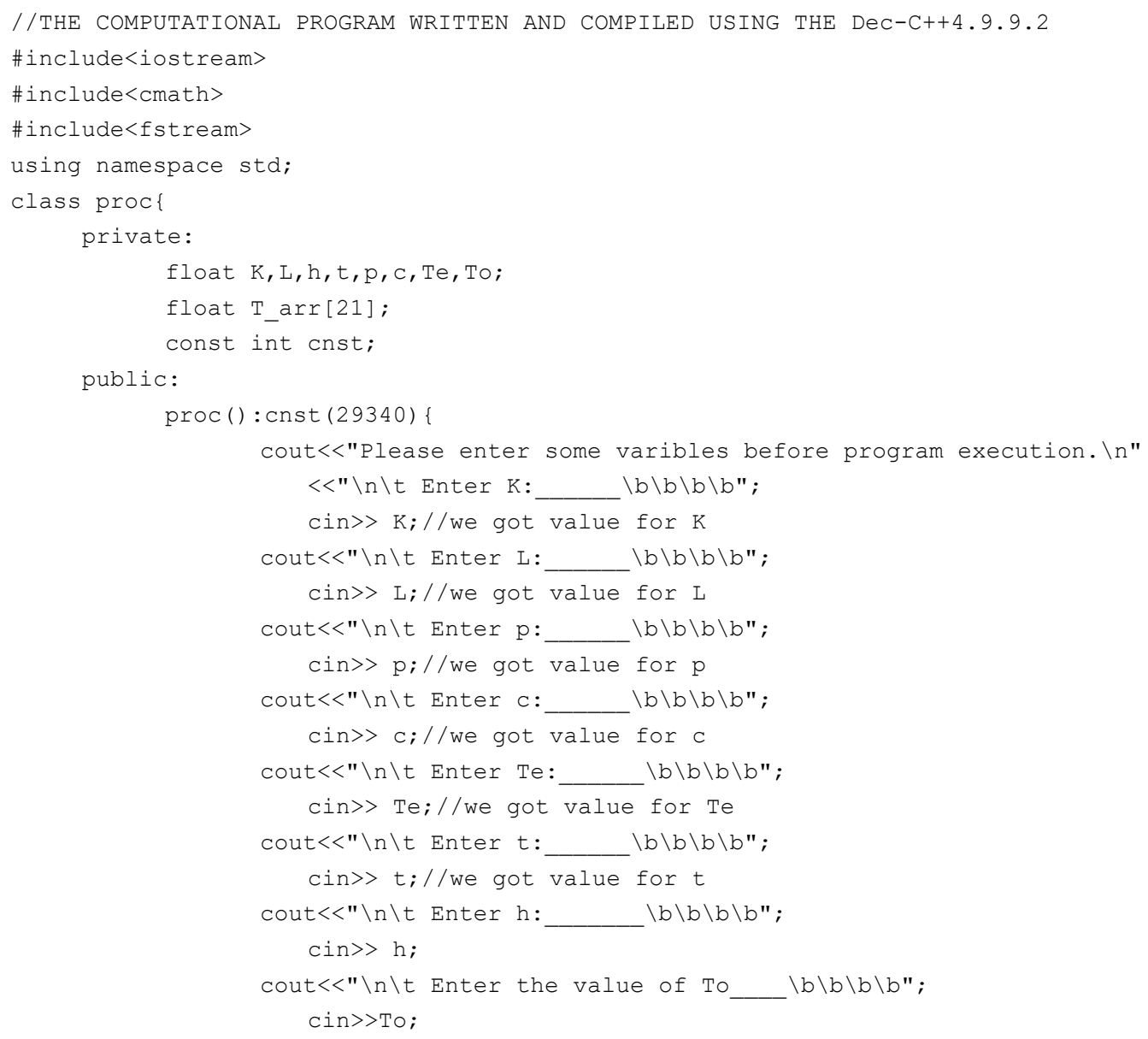




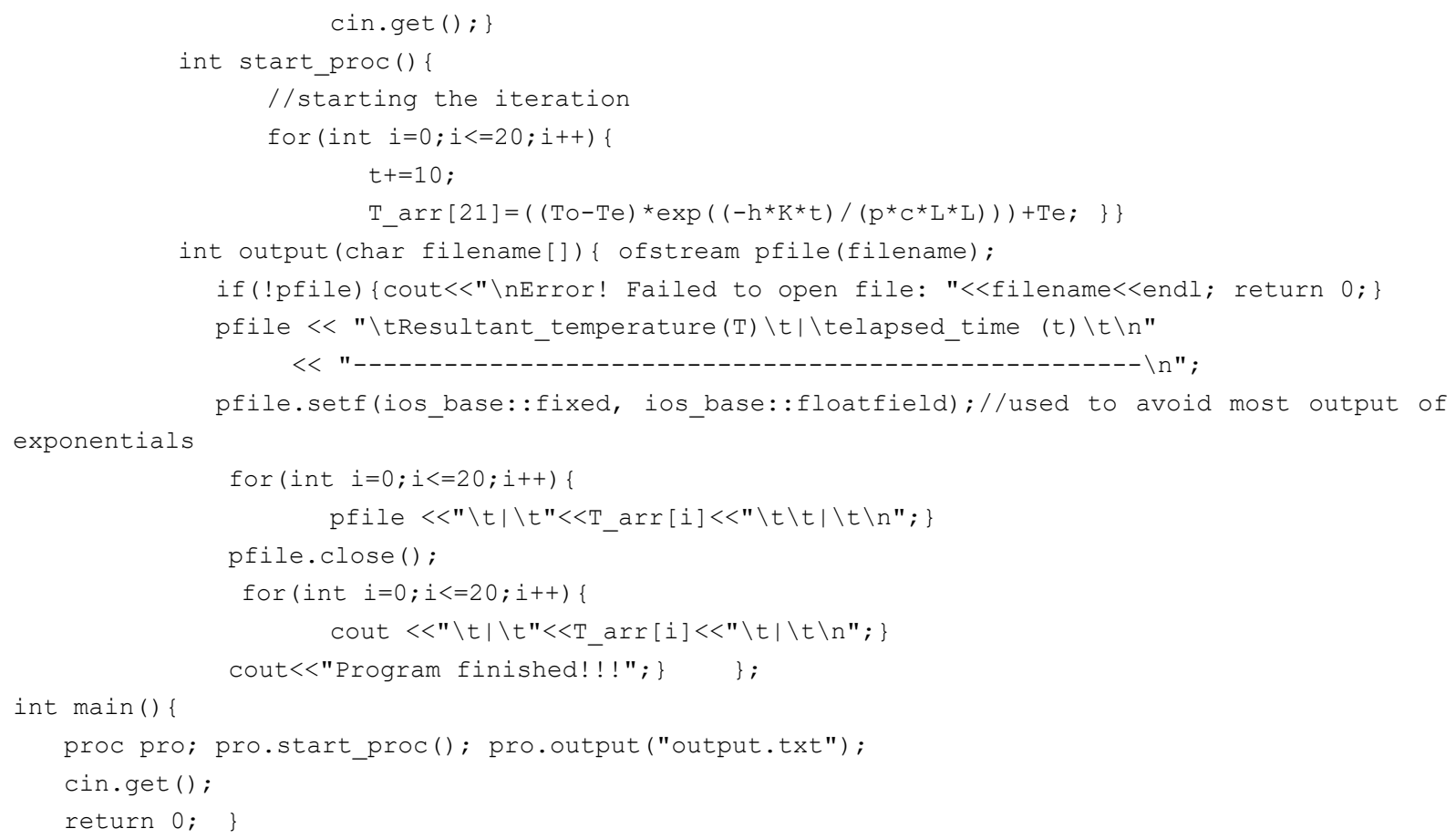

\section{Conflict of interests}

The authors declare that there is no conflict of interests regarding the publication of this paper.

\section{References}

Ahmad, S., Iqbal, Y., \& Muhammad, R. (2017). Effects of coal and wheat husk additives on the physical, thermal and mechanical properties of clay bricks. Boletín la Soc. Española Cerámica y Vidr., 56, 131-138.

Aramide, F. O. (2012). Effect of Firing Temperature on Mechanical Properties of Fired Masonry Bricks Produced from Ipetumodu Clay (pp. 70-82).

Chen, R. S., \& Ahmad, S. (2017). Mechanical performance and flame retardancy of rice husk/organoclay-reinforced blend of recycled plastics. Mater. Chem. Phys., 198, 57-65.

Dale et al. (2011). Thermal Properties and Thermal Modeling of Ballistic Clay Box. US Department of Commerce, National Institute of Standard and Technology (NIST). NISTIR 7840.

Folaranmi, J. (2009). Effect of Sawdust Additive on the Properties of Clay, 13, 53-56.

Garcia-avila, M., Portanova, M., \& Rabiei, A. (2014). Ballistic performance of a composite metal foam-ceramic armor system. Procedia Mater. Sci., 4, 151-156.

Glen, E. M. (1971). Analytical methods in conduction heat transfer (Vol. 508, pp. 217-284). Transient Heat Conduction. McGraw-Hill Book Company, New York (1971).

Johari, I., Said, S., Hisham, B., Bakar, A., \& Ahmad, Z. A. (2010). Effect of the Change of Firing Temperature on Microstructure and Physical Properties of Clay Bricks from Beruas (Malaysia), 42, 245-254.

Journal, A., \& Scientific, O. F. (2011). Effect of rice husk ash (RHA) on the properties of Ibaji burnt clay bricks, 674-677.

Kazmi, S. M. S., Abbas, S., Saleem, M. A., Munir, M. J., \& Khitab, A. (2016). Manufacturing of sustainable clay bricks: Utilization of waste sugarcane bagasse and rice husk ashes. Constr. Build. Mater., 120, 29-41.

Mukasey, M. B., Sedgwick, J. L., \& Hagy, D. W. (n. d.). Ballistic Resistance of Body Armor.

NIJ Standard-0101.06. (2008). Ballistic Resistance of Body Armour. US Department of Commerce, National Institute of Standard and Technology (NIST). NISTIR 7840.

Olgun, M. (2013). Cold Regions Science and Technology The effects and optimization of additives for expansive clays under freeze-thaw conditions. Cold Reg. Sci. Technol., 93, 36-46.

Oskouei, A. V., Afzali, M., \& Madadipour, M. (2017). Experimental investigation on mud bricks reinforced with natural additives under compressive and tensile tests. Constr. Build. Mater., 142, 137-147. 
Qatta, H. I. (2012). Improvement of the Mechanical and Thermal Properties of Clay Bricks by Using Local Materials in Iraq, 30, 3308-3327.

Rahman, A. (2014). Influence of Rice Husk Ash and Fly Ash on Properties of Red Clay.

Rickards, J. (2013). The lumped heat capacity method applied to target heating, 59, 328-334.

Silva, G. H. M. J. S. De., \& Mallwattha, M. P. D. P. (2018). Strength, durability, thermal and run-off properties of fired clay roof tiles incorporated with ceramic sludge. Constr. Build. Mater., 179, 390-399.

Silva, G. H. M. J. S. De., \& Perera, B. V. A. (2018). Effect of waste rice husk ash (RHA) on structural, thermal and acoustic properties of fi red clay bricks. J. Build. Eng., 18, 252-259.

Subramanian, R. S. (n. d.). Unsteady Heat Transfer: Lumped Thermal Capacity Model, 1-5.

Toure, P. M., Sambou, V., Faye, M., \& Thiam, A. (2017). Science Direct Mechanical and thermal characterization of stabilized earth bricks Assessing the feasibility of using the heat demand-outdoor temperature function for a long-term district heat demand forecast The 15th International Symposium on District Heating and Cooling. Energy Procedia, 139, 676-681.

Velasco, P. M., Ortíz, M. P. M., Giró, M. A. M., \& Velasco, L. M. (2014). Fired clay bricks manufactured by adding wastes as sustainable construction material-A review, 63, 97-107.

\section{Copyrights}

Copyright for this article is retained by the author(s), with first publication rights granted to the journal.

This is an open-access article distributed under the terms and conditions of the Creative Commons Attribution license (http://creativecommons.org/licenses/by/4.0/). 